\title{
Editorial
}

\section{Chronic Kidney Disease and the Aging Population}

\author{
Marcello Tonelli ${ }^{a} \quad$ Miguel Riellab \\ a University of Alberta, Edmonton, Alta., Canada; ${ }^{\mathrm{b} C}$ atholic University of Parana, Curitiba, Brazil
}

Youth, which is forgiven everything, forgives itself nothing: age, which forgives itself everything, is forgiven nothing. George Bernard Shaw

The proportion of older people in the general population is steadily increasing worldwide, with the most rapid growth in low- and middle-income countries [1]. This demographic change is to be celebrated, because it is the consequence of socioeconomic development and better life expectancy. However, population aging also has important implications for society - in diverse areas including health systems, labor markets, public policy, social programs, and family dynamics [2]. A successful response to the aging population will require capitalizing on the opportunities that this transition offers, as well as effectively addressing its challenges.

Chronic kidney disease (CKD) is an important public health problem that is characterized by poor health outcomes and very high health care costs. CKD is a major risk multiplier in patients with diabetes, hypertension, heart disease and stroke - all of which are key causes of death and disability in older people [3]. Since the prevalence of CKD is higher in older people, the health impact of population aging will depend in part on how the kidney community responds.

\section{KARGER}

(c) 2014 S. Karger AG, Basel

0250-8095/14/0393-0248\$39.50/0

E-Mail karger@karger.com

www.karger.com/ajn
March 13, 2014 will mark the celebration of the 9th World Kidney Day (WKD), an annual event jointly sponsored by the International Society of Nephrology and the International Federation of Kidney Foundations. Since its inception in 2006, WKD has become the most successful effort to raise awareness among policymakers and the general public about the importance of kidney disease. The topic for WKD 2014 is 'CKD in older people'. This article reviews the key links between kidney function, age, health and illness - and discusses the implications of the aging population for the care of people with CKD.

\section{Epidemiology of Aging}

The key drivers of population aging are socioeconomic development and increasing prosperity - which result in lower perinatal, infant and childhood mortality; lower risk of death in early adulthood due to accidents and unsafe living conditions; and improving survival of middle-aged and older people due to chronic disease. The resulting increases in life expectancy (together with the lower birth rates that typically accompany socioeconomic development) mean that older 
people account for a larger proportion of the general population [1].

In contrast to the situation even two generations ago, people can expect to live for many years after the usual retirement age. For example, UK men and women aged 65 years in 2030 can expect to live until age 88 and 91 years, respectively [4]. Although it is clear that people are living longer, it is uncertain how much of the increased life expectancy will translate into years of good health. These demographic changes have dramatic potential implications for conditions such as CKD, for which the prevalence increases with age.

\section{CKD Is Common in Older People and Its Prevalence Increases in Parallel with Age}

It has been known for decades that estimated glomerular filtration rate (eGFR) declines in parallel with age [5]. At older ages, an increased proportion of prevalent CKD cases has low eGFR alone (as compared to albuminuria alone, or both low eGFR and albuminuria) [6]. Although this might suggest that many older people with CKD can expect lower rates of kidney function loss, available data are inconclusive - and current knowledge does not allow clinicians to reliably distinguish between those whose CKD will and will not progress.

As for other age groups, the incidence of dialysis-dependent kidney failure has steadily increased among older people over the last few decades: in the US, a 57\% age-adjusted increase in the number of incident octogenarians and nonagenarians was noted between 1996 and 2003 alone [7], and the aging population will likely lead to continued increases in the number of older people with severe CKD.

\section{CKD Is Harmful but Treatable if Patients at Risk Are Identified}

Like younger people, older people with advanced CKD are at increased risk of death, kidney failure, myocardial infarction and stroke compared to otherwise similar people with normal or mildly reduced eGFR $[8,9]$. Although death is by far the most common of these adverse outcomes, older patients with clinically relevant CKD can still benefit from timely specialist referral; potential benefits include slower loss of kidney function (potentially preventing kidney failure), lower risk of cardiovascular events, and better information about the advantages and disadvantages of renal replacement [10].

Chronic Kidney Disease and the Aging

Population

\section{Dialysis Can Benefit Older People with Kidney Failure}

In developed countries, the default management strategy for older people with kidney failure appears to have shifted from conservative management to initiation of dialysis [11]. Although a large proportion of octogenarians who initiate dialysis will die within 6 months, a substantial minority may live for years. This heterogeneity in mortality is driven by differences in baseline comorbidity $[12,13]$ - and when functional status is lower at baseline, initiation of dialysis often signals the onset of further declines [14]. Although available data have limitations, quality of life appears reasonable among selected older dialysis patients - and can remain stable despite substantial comorbidity $[15,16]$.

These data suggest that dialysis is an appropriate treatment option for well-informed older patients with kidney failure - especially for those with good baseline quality of life. On the other hand, the very poor outcomes experienced in those with more comorbidity or lower functional status at baseline clearly demonstrate that dialysis does not improve clinical outcomes for all older people with kidney failure - and that good clinical judgment and careful communication will be increasingly required as the general population continues to age.

\section{Kidney Transplantation Can Also Benefit Older People with Kidney Failure}

Older age alone does not preclude kidney transplantation in otherwise suitable candidates. However, older patients with kidney failure are more likely to have contraindications to transplantation, and are less likely to be placed on the kidney transplantation waiting list. Unsurprisingly, patient and graft 5-year survival probabilities are lower among US kidney transplant recipients aged $\geq 65$ years as compared to those aged $35-49$ years (patient: 67.2 vs. $89.6 \%$; graft: 60.9 vs. $75.4 \%$, respectively) [17].

Nonetheless, transplantation appears to reduce mortality among patients of all ages [17]. Use of expanded criteria deceased donors $[18,19]$ as well as more liberal use of older living donors [20] also appear to reduce mortality among older people with kidney failure, as compared to similar patients who remain on the transplant waiting list. These latter two strategies are especially appealing for use in developing countries, where growth in the prevalence of older people has been most pronounced. However, because transplant surgery itself temporarily

Am J Nephrol 2014;39:248-251 


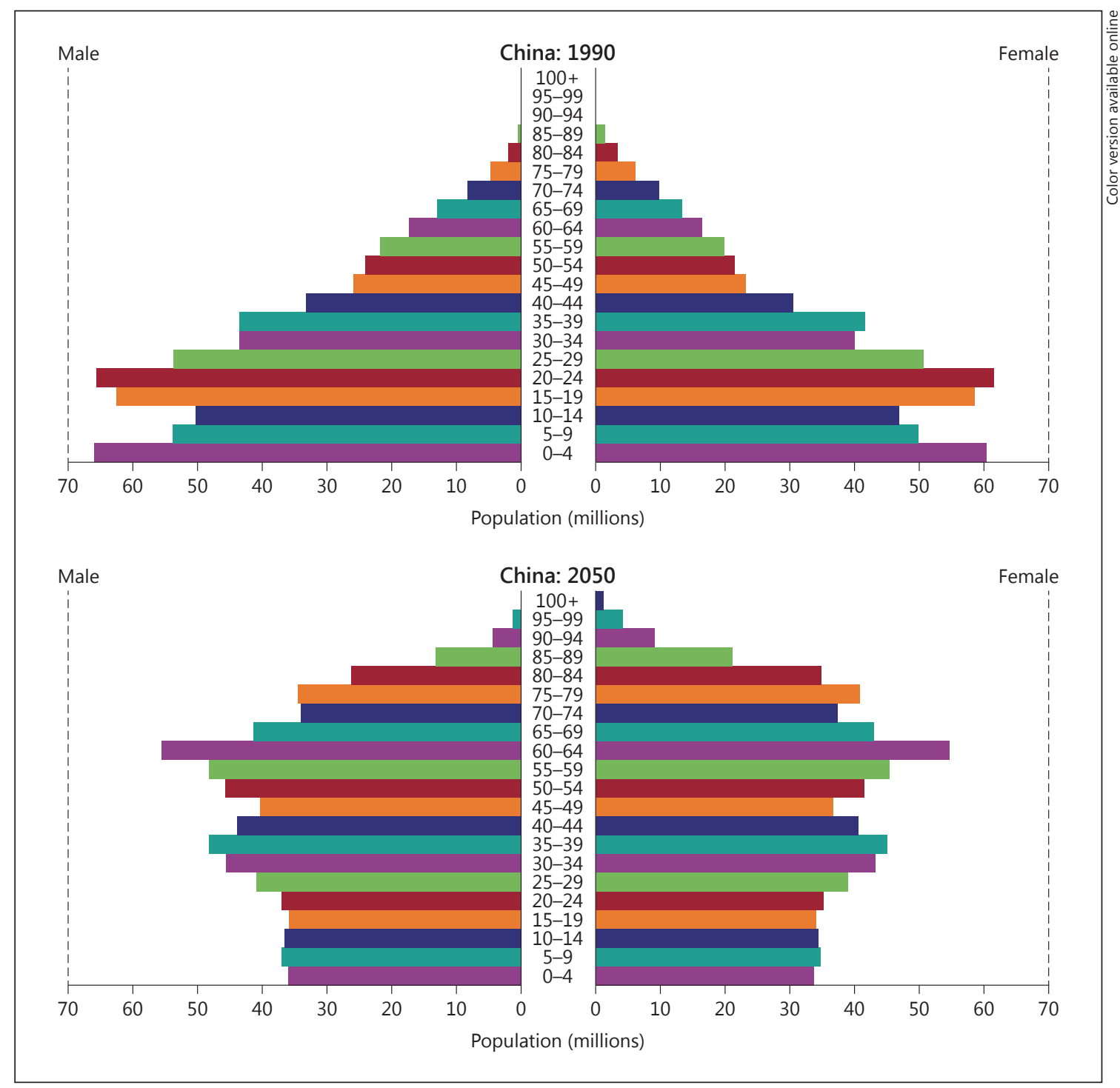

Fig. 1. Changing population age structure for China 1990-2050.

increases the risk of death, the mortality benefits associated with kidney transplantation (regardless of donor type) are restricted to those with reasonable baseline life expectancy and without dramatically increased perioperative risk [21].

\section{The Way Forward}

The aging of the general population means that older people now account for a much greater proportion of patients with or at risk for kidney disease and kidney fail- ure. The tremendous clinical heterogeneity within this population indicates the need for more discerning management. Chronological age alone will not be sufficient as the basis for clinical decisions, and a more nuanced approach is required - based on the comorbidities, functional status, quality of life and preferences of each individual patient. Clinicians can be reassured that dialysis and kidney transplantation can increase life expectancy - and will allow reasonable quality of life in selected older people with kidney failure. Perhaps more importantly, clinicians, patients and their families can be comforted by the knowledge that timely specialist evaluation 
can help to improve outcomes and reduce symptoms in older people with advanced kidney disease - whether they have selected conservative management or dialysis as their treatment plan.

\section{Acknowledgements}

Dr. Tonelli was supported by a Government of Canada research chair in the optimal care of people with chronic kidney disease.

\section{References}

1 World Health Organization: Good health adds life to years: global brief for World Health Day 2012. Geneva, WHO, 2012.

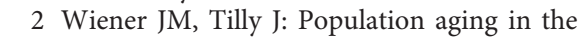
United States of America: implications for public programmes. Int J Epidemiol 2002;31: 776-781.

3 Couser WG, Remuzzi G, Mendis S, et al: The contribution of chronic kidney disease to the global burden of major noncommunicable diseases. Kidney Int 2011;80:1258-1270.

4 Select Committee on Public Service and Demographic Change: Ready for aging? Report. London, House of Lords, 2013.

5 Davies DF, Shock NW: Age changes in glomerular filtration rate, effective renal plasma flow, and tubular excretory capacity in adult males. J Clin Invest 1950;29:496-507.

-6 James MT, Hemmelgarn BR, Tonelli M: Early recognition and prevention of chronic kidney disease. Lancet 2010;375:1296-1309.

7 Kurella M, Covinsky KE, Collins AJ, et al: Octogenarians and nonagenarians starting dialysis in the United States. Ann Intern Med 2007; 146:177-183.

8 Hemmelgarn BR, Manns BJ, Lloyd A, et al: Relation between kidney function, proteinuria, and adverse outcomes. JAMA 2010;303: 423-429.
99 O'Hare AM, Bertenthal D, Covinsky KE, et al: Mortality risk stratification in chronic kidney disease: one size for all ages? J Am Soc Nephrol 2006; 17:846-853

10 Stevens PE, Levin A, Kidney Disease: Improving Global Outcomes Chronic Kidney Disease Guideline Development Work Group Members: Evaluation and management of chronic kidney disease: synopsis of the kidney disease: improving global outcomes 2012 clinical practice guideline. Ann Intern Med 2013; 158:825-830.

11 Thorsteinsdottir B, Montori VM, Prokop LJ, et al: Ageism vs. the technical imperative, applying the GRADE framework to the evidence on hemodialysis in very elderly patients. Clin Interv Aging 2013;8:797-807.

12 Chandna SM, Da Silva-Gane M, Marshall C, et al: Survival of elderly patients with stage 5 CKD: comparison of conservative management and renal replacement therapy. Nephrol Dial Transplant 2011;26:1608-1614

13 Murtagh FE, Marsh JE, Donohoe P, et al: Dialysis or not? A comparative survival study of patients over 75 years with chronic kidney disease stage 5. Nephrol Dial Transplant 2007; 22:1955-1962.
14 Kurella Tamura M, Covinsky KE, Chertow GM, et al: Functional status of elderly adults before and after initiation of dialysis. N Engl J Med 2009;361:1539-1547.

15 Lamping DL, Constantinovici N, Roderick P, et al: Clinical outcomes, quality of life, and costs in the North Thames Dialysis Study of elderly people on dialysis: a prospective cohort study. Lancet 2000;356:1543-1550.

16 Unruh ML, Newman AB, Larive B, et al: The influence of age on changes in health-related quality of life over three years in a cohort undergoing hemodialysis. J Am Geriatr Soc 2008;56:1608-1617.

17 Knoll GA: Kidney transplantation in the older adult. Am J Kidney Dis 2013;61:790-797.

$\checkmark 18$ Merion RM, Ashby VB, Wolfe RA, et al: Deceased-donor characteristics and the survival benefit of kidney transplantation. JAMA 2005;294:2726-2733.

19 Cohen B, Smits JM, Haase B, et al: Expanding the donor pool to increase renal transplantation. Nephrol Dial Transplant 2005;20:34-41.

20 Gill J, Bunnapradist S, Danovitch GM, et al: Outcomes of kidney transplantation from older living donors to older recipients. Am J Kidney Dis 2008;52:541-552.

21 Gill JS, Tonelli M, Johnson N, et al: The impact of waiting time and comorbid conditions on the survival benefit of kidney transplantation. Kidney Int 2005;68:2345-2351. 